\title{
ARTYKUŁY
}

http://dx.doi.org/10.15762/ZH.2019.05

BARTOSZ AWIANOWICZ

(Uniwersytet Mikołaja Kopernika w Toruniu)

\section{Opisy Gdańska i Torunia w relacjach Petera Mundy'ego \\ Między szczerą ciekawością Anglika \\ A WCZESNONOWOŻYTNĄ TEORIĄ EKFRAZY}

Słowa kluczowe: Peter Mundy, Gerard Bucoldianus, Gdańsk, Toruń, retoryka, ekfraza, literatura podróżnicza, ciekawość

Rzeczpospolitą, w tym Prusy Królewskie, zwłaszcza zaś Gdańsk, na przestrzeni XVI i XVII w. odwiedziło wielu mieszkańców Wysp Brytyjskich, z których przynajmniej 11 pozostawiło pisemne relacje ze swych peregrynacji: Jerome Horsey, Fynes Moryson, Thomas Roe, Wiliam Lithgow, Peter Mundy, Robert Bargrave, Patrick Gordon, Laurence Hyde, Robert South, Bernard Connor i anonimowy autor A Relation of the State of Polonia ${ }^{1}$. Peter Mundy (1596 - ok. 1667), syn kupca z Kornwalii, który - jak się wydaje - swą edukację odbył w dużym stopniu na morzu jako chłopiec okrętowy, służący na statkach pływających do Francji i Hiszpanii, a następnie młody kupiec, podróżując po Morzu Śródziemnym do Konstantynopola, w opinii Dorothy Carrington był postacią szczególnie reprezentatywną dla swoich czasów: „W epoce, w której ciekawość była cechą charakterystyczną inteligentnych Anglików, pasja poznawcza była najważniejszą namiętnością jego życia. [...] Jego niezaspokojony głód informacji, oko do detali, dążność do dokładności uczyniłyby z niego w dzisiejszych czasach pierwszorzędnego naukowca”2. Agnieszka White natomiast zwraca uwagę na obecną w dziele Mundy'ego dehierarchizację treści, w której pozostaje jedynie porządek chronologiczny, a poza tym autor opisuje „najdrobniejsze, często przypadkowe i skrajnie różne elementy rzeczywistości, które w jakikolwiek sposób wzbudziły zainteresowanie peregrynanta. [...] Różnorodność zapisków angielskiego kupca potwierdza wielokierun-

${ }^{1}$ Zob. Agnieszka White, Obraz kultury Rzeczypospolitej w angielskich relacjach podróżniczych (koniec XVI i XVII wiek), Warszawa 2014, s. 6, 29-68.

${ }^{2}$ Dorothy Carrington, The Traveller's Eye, London 1949, s. 178-179. Przekład za: A. WhiTE, op.cit., s. 62. 
kowość jego zainteresowań, wychodzących daleko poza prowadzoną działalność zawodową"3.

Celem artykułu jest bliższe przyjrzenie się opisom najważniejszych miast Prus Królewskich: Gdańska i Torunia w kontekście wczesnonowożytnej teorii ekfrazy ${ }^{4}$ i pochwały miast, by na ich podstawie spróbować odpowiedzieć na pytanie, na ile opisy Mundy’ego są swobodną formą będącą wynikiem samej tylko „pasji poznawczej inteligentnego Anglika”, by posłużyć się określeniem dwudziestowiecznej brytyjskiej badaczki, na ile zaś konstruktem silnie zakorzenionym w formie wypracowanej w szkole humanistycznej XVI i początku XVII w. ${ }^{5}$

Należy zatem zacząć od informacji o wykształceniu młodego Petera i przedstawić pokrótce jeden z najważniejszych i najszerzej dostępnych podręczników retoryki, z którym mógł się w swym curriculum zetknąć. Głównym źródłem do życia angielskiego podróżnika pozostaje manuskrypt jego dzieła, wydany w całości dopiero w latach 1907-1936 , w którym okresu młodzieńczego, konkretnie lat 1608-1617, dotyczy pierwsza z jego Relations ${ }^{7}$. Dowiadujemy się z niej, że po raz pierwszy Mundy opuścił dom rodzinny w kornwalijskim Penryn w roku 1608, udając się z ojcem do Rouen, następnie wspomina swoją naukę języka francuskiego w Bayonne w 1610 r. oraz odbyte w latach 1611-1613 podróże do Barramedy, Kadyksu, Malagi oraz San Lucar, dalej pobyt w Sewilli w latach 1615-1617 i wreszcie wyprawę do Konstantynopola w 1617 r. Odnotowuje tam nie tylko cel rocznej wizyty w Bayonne (nauka francuskiego),

${ }^{3}$ A. White, op.cit., s. 61.

${ }^{4}$ Terminy ekfraza, deskrypcja i opis traktuję wymiennie zgodnie $\mathrm{z}$ ich rozumieniem w teo-

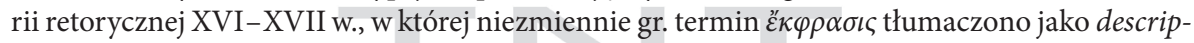
tio - zob. Bartosz B. Awianowicz, Progymnasmata $w$ teorii i praktyce szkoły humanistycznej od końca XV wieku do połowy XVIII wieku. Dzieje nowożytnej recepcji Aftoniosa od Rudolfa Agricoli do Johanna Christopha Gottscheda, Toruń 2008, s. 171-172. Na temat terminologii związanej z descriptio i jej przekładu jako „opis” zob. Heinrich LAUsBerg, Retoryka literacka. Podstawy wiedzy o literaturze, przełożył, opracował i wstępem poprzedził Albert GoRzkowski, Bydgoszcz 2002, s. 443, 449 (pojawia się tam również jako konkretne określenie „opisu” / „przedstawie-

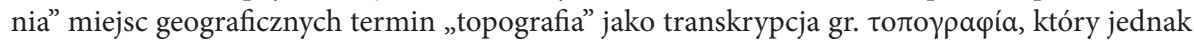
z uwagi na jego inny zakres semantyczny we współczesnym języku polskim jest mało funkcjonalny).

${ }^{5}$ Części teoretyczne podręczników retoryki czytanych w ówczesnych szkołach humanistycznych były zasadniczo zbieżne w protestanckich gimnazjach, jak też w kolegiach jezuickich, a także w wielu szkołach niższego szczebla w ośrodkach różnowierczych i katolickich. Różnice widać dopiero na poziomie doboru egzemplów - por. Bartosz AwiAnowicz, Die Progymnasmata-Sammlungen und der Glaubenskampf des 17. Jahrhunderts, [in:] Welche Antike? Konkurrierende Rezeptionen des Altertums im Barock, Bd. 1, hrsg. v. Ulrich HeInEN, Wiesbaden 2011, s. $480-489$.

${ }^{6}$ The Travels of Peter Mundy in Europe and Asia 1608-1667, vol. 1-5, ed. by Richard Carnac Temple, London 1907-1936 (dalej cyt. The Travels of Peter Mundy).

${ }^{7}$ Zob. The Travels of Peter Mundy, vol. 1, s. 13-40. 
lecz także dwuletniego pobytu w Sewilli, gdzie uczył się z kolei języka hiszpańskiego ${ }^{8}$. Nie dowiadujemy się natomiast z pierwszej „relacji” Mundy’ego, czego uczył się we Francji i Hiszpanii poza językami, ani jaką edukację zdobył w rodzinnej Kornwalii lub w Londynie. Można jednak z dużym prawdopodobieństwem założyć, że na którymś z etapów swej edukacji zetknął się z niezmiernie popularnym łacińskim przekładem Progymnasmatów greckiego retora Aftoniosa $\mathrm{z}$ komentarzem (scholiami) marburskiego profesora Reinharda Loricha, który od pierwszego wydania w 1542 r. do 1718 r. miał przeszło 150 wydań w całej niemal Europie ${ }^{9}$. Owa edycja była, jak zapewniał Richard Rainolde, autor jej angielskiej parafrazy z 1563 r. pt. A book called the Foundacion of Rhetori$k e$, podręcznikiem stosowanym powszechnie również w szkołach angielskich ${ }^{10}$. Oczywiście nie był to jedyny podręcznik, z którego młody Brytyjczyk mógł poznać teorię opisu lub pochwały miast. Jej zarys był obecny choćby w równie popularnych De arte rhetorica libri tres hiszpańskiego jezuity Cypriana Soareza (ks. I, 49), jednak w postaci znacznie bardziej lakonicznej, ograniczonej do pół strony kieszonkowego formatu $32^{\circ 11}$. Zbyteczne natomiast wydaje się przytaczanie w kontekście zapisków Mundy’ego szerokiego kontekstu silnie zretoryzowanych poetyckich opisów miast ${ }^{12}$, gdyż dziełu peregrynanta z Kornwalii przyświecało raczej podejście geografa Pomponiusza Meli wyrażone w I w.n.e. (De chorographia 1,1): „Przystępuję do opisu Ziemi; jest to dzieło trudne, które zupełnie nie nadaje się do upiększeń retorycznych [facundiae minime ca-

${ }^{8}$ Zob. The Travels of Peter Mundy, vol. 1, s. 13: „I was sent to Bayon in Gascony to learne the French Tongue, where, haveing remayned one yeare”; ibid., s. 14: „I was sent upp to the Cittie of Sevill to remaine with Mr. Charles Partker [...], where I lived two yeares more, and in that tyme attained the Spanish Tongue".

${ }_{9}^{9}$ Zob. B. B. Awianowicz, Progymnasmata, s. 108.

${ }^{10}$ Zob. Thomas Whitfield BALDwin, William Shakespere's Small Latine \& Lesse Greek, vol. 2, Urbana 1944, s. 288.

${ }^{11}$ Zob. np. Cyprian SoArez, De arte rhetorica libri tres, ex Aristotele, Cicerone et Quintiliano praecipue deprompti [...], Coloniae 1590, s. 49. Na temat popularności tego podręcznika i jego licznych wydań m.in. w Hiszpanii i Francji zob. Lawrence D. Green, James J. Murphy, Renaissance Rhetoric. Short-Title Catalogue 1460-1700, Hunts 2006, s. 417-419. Jeszcze mniej miejsca pochwałom i opisom miast poświęca wciąż wielokrotnie przedrukowywana i dość chętnie czytana w XVII w. Institutio oratoria Kwintyliana $(3,7,26)$. Szerzej na temat antycznych (i średniowiecznych) pochwał i opisów miast zob. Carl Joachim Classen, Die Stadt im Spiegel der Descriptiones und Laudes urbium in der antiken und mittelalterlichen Literatur bis zum Ende des zwölften Jahrhunderts, Hildesheim 1980; Roman KRZYwy, Deskrypcja Stambulu w „Przeważnej legacyi" Samuela Twardowskiego wobec topiki laudatio urbis, Pamiętnik Literacki, t. 102: 2011, z. 4, s. 41-45; idem, Wędrówki z Mnemozyne. Studia o topice dawnego podróżopisarstwa, Warszawa 2013, s. 73-88.

${ }^{12}$ Tego, jak przemyślaną strukturę i bogatą metaforykę mogły mieć poetyckie opisy miast w poezji końca XVI w., przekonująco dowodzą na przykładzie hodoeporikonu Jana Rybińskiego autorzy wstępu do: Jan RyBiŃski, Księga elegii podróżnych, przekład Elwira Buszewicz, wstęp i opracowanie Elwira Buszewicz, Wojciech Ryczek, Warszawa 2015, s. 29-45. 
pax - B.A.]. Zawiera bowiem omal tylko nazwy ludów i miejscowości w układzie dość zawilym; temat to raczej obszerny niż przyjemny"13. Różnica polega tu jednak na tym, że autor Relations nigdzie się nie uskarża na ich formę, bo też w przeciwieństwie do Rzymianina jest bardziej człowiekiem interesu i podróżnikiem niż literatem.

Można zatem pozostawić na boku wczesnonowożytne poetyckie ekfrazy oraz mowy - panegiryki na cześć miast rodzinnych lub odwiedzanych. Wciąż jednak wartościowe poznawczo będzie bliższe przyjrzenie się teorii zawartej w podręczniku Progymnasmatów, z którym Mundy mógł się zetknąć w młodym wieku i mógł się do niego (choćby podświadomie) odwoływać. Otóż Lorich do swych scholiów, którymi opatrzył Aftoniosową teorię pochwały (laus) oraz przykłady tak greckiego retora, jak i swe własne, dodał rozdział Copiosa urbis laudandi ratio, ex Bucoldiano, zaczerpnięty z De inventione et amplificatione oratoria, seu usu locorum libri tres czynnego w pierwszej połowie XVI w. filologa i lekarza Gerarda Bucoldianusa (znanego też jako Gerard Bucholds, Gerhard Bucholtz lub Bucoltz).

Teoria ta, w znacznym stopniu oparta na dziele Menandra z Laodycei (III w.n.e.), obejmuje następujące rozdziały: XVHI: Quae urbes ex locis copiose laudandi ratio (Jaki jest sposób chwalenia miast według punktów); XIX: Urbis laus a conditore, per locos ducitur (Pochwała miasta ze względu na założyciela, przeprowadzony przez topoi), XX: Urbis laus ab iis, quae huic simul tempore coniuncta sunt, \& primum ab aeris temperie < per $>$ locos ducitur (Przeprowadza się poch watę miasta przez topoi właściwe dla tego, co łącznie jest związane z czasem obecnym, a przede wszystkim dla umiarkowanego klimatu) oraz XXI: Laus urbis ab agris, fluminibus, publicis item munitionibus, tectis, ipsisque civibus, per locos ducitur (Przeprowadza się pochwałe miasta przez topoi właściwe dla gruntów, rzek, jak też wspólnych obwarowań, budynków oraz samych obywateli $)^{14}$. Pierwszy z owych rozdziałów okazuje się dla naszych rozważań o ekfrazach Petera Mundy’ego właściwie nieistotny, gdyż w rozdziale XVIII Bucoldianus skupia się na polemice $\mathrm{z}$ twierdzeniem Kwintyliana, że miasta chwali się w ten sam sposób, co ludzi. Rozdział XIX zaś poświęca charakterystyce osoby założyciela miasta ${ }^{15}$. W ekfrazach angielskiego kupca i podróżnika brakuje

${ }^{13}$ Przekład Mariana Goliasa za: Pomponiusz Mela, Chorograpphia czyli Opis kręgu Ziemi, red. Sergiusz Szary PKIn, Krzysztof Tomasz WitczaK, nowa poprawiona redakcja tłumaczenia Mariana Goliasa - Krzysztof Tomasz Witczak, Piotrków Trybunalski 2011, s. 37.

${ }^{14}$ Zob. Gerardus Bucoldianus, De inventione et amplificatione: seu usu locorum, libri tres, Lugduni 1551, s. 90-97; Aphthonius Sophista, Progymnasmata. Partim a Rodolpho Agricola, partim a Ioanne Maria Catanaeo Latinitate donata. Cum luculentis \& utilibus in eadem Scholiis Reinhardi Lorichii Hadamarii, Lugduni 1640, s. 316-329.

${ }^{15}$ Dokładne omówienie tych rozdziałów oraz stopnia ich zależności od Menandra Retora w: Bartosz B. Awianowicz, „Urbes laudandi ratio”. Antyczna teoria pochwaly miast i jej recep- 
szerszej perspektywy historycznej, nawet w odniesieniu do miast o tak bogatej i dobrze udokumentowanej historii, jak Konstantynopol ${ }^{16}$.

Więcej zbieżności z teorią Bucoldianusa i opisami praktyka Mundy’ego odnajdujemy, zestawiając z opisami Anglika zalecenia z kolejnego (XX) rozdziału autora: De inventione et amplificatione oratoria. Teoretyk zaleca w nim bowiem, by wyjaśniać przyczyny, dlaczego założyciel wybrał właśnie to miejsce na lokację miasta („cur eo in loco urbem locarit”). Przy tej okazji należy przedstawić pożytki płynące z położenia nad morzem lub w głębi lądu oraz wprowadzić porównanie z ziemią i usytuowaniem innych miast („conferendo hanc cum aliarum urbium agro, situque”), co ma wykazać, że chwalone miasto leży w okolicy „albo bardziej urodzajnej, albo przynajmniej porównywalnej, w żadnym wypadku nie gorszej” ( „aut fertiliorem, aut certe parem esse, nullaque in re deteriorem"). Nadto znalazły się tu zalecenia, by opisać ustanowione w danym mieście prawa (leges) i zasady moralne (religio), dzięki którym obywatele żyją „w sprawiedliwości, obyczajnie i bogobojnie” („iuste, modeste, pieque”), jak również rozbudzone przez założyciela „już na samym początku istnienia miasta zainteresowania literackie i sztuką wojenną” („simul cum urbis primordijs literarum bellique studia”). Według Bucoldianusa warto też przedstawić świadectwa czyjejś uczoności („cuiusque eruditionis testimonia”), jak też „męstwo i dzielność okazane w walce bądź to przez wszystkich, bądź też poszczególnych obywateli” („nunc uniuersum, nunc singulorum militiae fortitudo, uirtusque") ${ }^{17}$.

Należy pamiętać, że prymarnym celem Mundy’ego nie była retoryczna pochwała (łac. laus, ang. praise), a jedynie opis (łac. descriptio, ang. description) miejsc, do których dotarł, oraz przedmiotów i zjawisk, które oglądał. Jest to dobrze widoczne w jego opisach Gdańska i Torunia, które odwiedził podczas swych europejskich wojaży w latach 1640 i 1642 . Opisując zatem np. bliskie zarówno kategoriom leges, jak i religio różne formy egzekwowania sprawiedliwości („execucion of Justice”) w Gdańsku ${ }^{18}$, czyni to nie tyle by pochwalić, ile, by ukazać „rozmaite sposoby wymierzania kar” („sundry Manner of waies”), choć pozwala sobie również na wartościujące komentarze, jak np. opis ścięcia ( „Beheading”) kończy stwierdzeniem: „Wszystko to odbywa się nagle: łaskawy rodzaj śmierci dla przestępcy zarówno jeśli chodzi o cierpienie, jak i wykonanie” („All this sodainely perfformed: a generous kind of death for an offender both in the sufferance and execution"). Niejako zgodnie z zaleceniem niemieckiego teoretyka, by opis zwyczajów okrasić testimonium - świadectwem, czy

cja $w$ „De inventione et amplificatione oratoria” Gerarda Bucoldianusa oraz $w$ „Essercitii di Aftonio Sofista" Orazia Toscanelli, Terminus, t. 11: 2009, z. 1-2, s. 22-23.

${ }^{16}$ Zob. The Travels of Peter Mundy, vol. 1, s. 25-40.

${ }^{17}$ Szerzej zob. B. B. Awianowicz, „Urbes laudandi ratio”, s. 23-24.

${ }^{18}$ Zob. The Travels of Peter Mundy, vol. 4, s. 172-177. 
też przykładem, wprowadza tu Anglik również „a strange story”"19 ilustrującą opis kar śmierci przypadkiem pewnego młodzieńca, który miał zostać stracony za morderstwo 6 sierpnia 1632 r. o godzinie dziewiątej rano, lecz na miejscu kaźni pojawił się niejaki Hans Tetelhofftt. Krzyknął on, że skazaniec jest niewinny („the Man is Innocent”) i sam przyznał się do zbrodni, a wyrok śmierci wykonano na nim jeszcze tego samego dnia o godzinie dwunastej. Krzywoprzysięzcom, którzy zeznawali przeciw młodzieńcowi, obcięto po dwa palce. Wprawdzie Mundy rezygnuje z opatrzenia tej „dziwnej historii” wartościującym komentarzem, ale można potraktować ten opis jako przykład sprawnego działania wymiaru sprawiedliwości w Gdańsku. Tę interpretację exemplum Anglika jako elementu enkomionu osłabia wszakże początek kolejnego rozdziału o karach, w którym Mundy stwierdzał: „powiedziałem tak dużo o egzekucjach, ponieważ część z nich różni się o tych stosowanych u nas" ${ }^{20}$. W opisie Gdańska angielski peregrynant zastosował również postulowane przez Bucoldianusa (ale także Aftoniosa) porównanie (comparatio), zasygnalizowane już w podtytule pierwszego rozdziału „relacji” XXXV: „Gdańsk: jego porównanie z Londynem” („Dantzigk: itts comparison with London”21). Jest to zresztą zestawienie nie tylko ze stolicą Anglii, lecz także z bliższym nadbałtyckiej metropolii Amsterdamem, który pojawia się jako punkt odniesienia już w zdawkowej charakterystyce położenia Gdańska w „relacji” XXXIII².

Podróżnikiem z Kornwalii zdaje się bardziej niż zasady pochwały miast lub ich ekfrazy kierować wczesnonowożytna curiosity - ciekawość, o której Alexander Marr pisał jako o jednym z dwóch konceptów (obok wonder), które są bardzo mocno obecne przez cały okres wczesnej nowożytności, od renesansu do oświecenia ${ }^{23}$. Jeszcze bardziej uwidacznia się owa tendencja opisywania ciekawostek w zestawieniu opisów Mundy’ego z teorią rozdziału XX księgi II Bucoldianusowego traktatu, tj. Pochwały miasta od gruntów, rzek, jak też wspólnych obwarowań, budynków oraz samych obywateli ${ }^{24}$. Poświęcony jest on pochwale miasta ze względu na klimat („quo in climate”), który ma być przede wszystkim łagodny („aeris temperies”), oraz ze względu na związany z klimatem urodzaj okolicy otaczającej miasto: „Następnie trzeba będzie powiedzieć

19 „I have said soe much off executions beecause som off them vary From those used with us"; ibid., s. 174-175.

${ }^{20}$ Ibid., s. 175.

${ }^{21}$ Ibid., s. 167.

22 Zob. ibid., s. 89.

${ }^{23}$ Alexander MARr, Introduction, [in:] Curiosity and Wonder from the Renaissance to the Enlightenment, ed. by Robert J. W. Evans, Alexander MARr, Aldershot 2006, s. 1-18 (tam też bardzo rzetelny przegląd opracowań, w których w ciągu ostatnich dziesięcioleci analizowano kategorie wonder i curiosity oraz ich wzajemne relacje).

${ }^{24}$ Taka skrócona wersja tytułu: Laus urbis ab agris, fluminibus, publicis item munitionibus, tectis, ipsisque civibus - zob. ApHthonius Sophista, op.cit., s. 320. 
o polach, z którymi miasto sąsiaduje, o rzekach, jeziorach, stawach, górach, o morzu, jeśli jest w pobliżu, albo bezpośrednio oblewa miasto. Odnośnie tego wszystkiego zaś należy wynieść w pochwałach to, co żyzne i przyjemne, o tym poucza nas topika właściwego dla wszystkiego atrybutu: mianowicie, że pola są urodzajne, rzeki bogate w ryby i zdatne do żeglugi, góry porośnięte winną latoroślą, wreszcie, że po morzu pływa wiele statków"25.

Bucoldianus wspomina dalej, że można wspomnieć, czy miasto leży blisko granic, czy też w centrum jakiegoś kraju, o czym obszernie („copiose”) pisali Grecy: „[...] zwłaszcza retor Menander, który pozostawił osobne pismo o pochwale. Jednakże, podczas gdy pisząc o chwaleniu uczenie przedstawił okoliczności związane z położeniem miejsca, co jest tematem niewyczerpanym, nawet nie wspomniał o tym, czego w żadnym razie nie należało pomijać, mianowicie o tym, jakie są wspólne obwarowania i znajdujące się wewnątrz nich budynki obywateli"26.

Mundy w swych opisach, zarówno Gdańska, jak i Torunia, zdaje się najbardziej korzystać właśnie z tej części teorii retorycznego (pochwalnego) opisu. Oto początek opisu Torunia z XXXIII „relacji” Anglika: „Toruń jest dobrze rozplanowanym miastem i przyjemnym miejscem. Położony nad rzeką Wisłą, otoczony murami, pełnymi baszt, z 9 lub 10 bramami. Ma czyste, proste ulice, najlepszy ratusz w całym tym kraju [tj. w Polsce lub na Pomorzu - B.A.], trochę przypominający giełdę, bardzo duży i wysoki, ma cztery skrzydła w kwadracie i dziedziniec pośrodku, góruje nad nim wyniosła, kosztownie zdobiona wieża"27.

Zgodnie z zaleceniami Bucoldianusa mamy tu podkreślenie dobrego położenia miasta nad rzeką, następnie charakterystykę obwarowań, potem dopiero znajdujących się wewnątrz nich ulice i budynku ratusza. Opis Gdańska, rozpoczynający się, jak zaznaczyłem wcześniej, od porównania jego wielko-

${ }^{25}$ G. Bucoldianus, op.cit., s. 93: „Deinde dicendum erit de agris, qui adiacent: de fluminibus, stagnis, piscinis, montibus, ipsoque mari, si aut uicinum est, aut urbem alluit. In ijs autem omnibus ea, quae fructuosa amoenaque sunt, laudibus uehenda esse idem qui omnium, adiunctorum nos locus admonet. Siquidem agros fertiles, fluuios piscosos, nauigabilesque, montes uitibus consitos, tum mare nauibus frequentatum" [tłum. B.A.].

${ }^{26}$ Ibid., s. 93-94: „praesertim Menander rhetor, qui de laude seorsum scripta reliquit. Verum dum hic in laudando ex loci positione circumstantias, quod infinitum est, studiose prosequitur, eorum quae omitti minime debuissent, quae uidelicet publicae munitiones, interiorque ciuium structura esset, ne meminit quidem" [tłum. B.A.]. Szerzej o tym rozdziale zob. B. B. Awianowicz, „Urbes laudandi ratio”, s. 26-28.

${ }^{27}$ The Travels of Peter Mundy, vol. 4, s. 99: „Thorun [Thorn] is a well contrived Citty and a pleasant place, Seated on the River Weessell [Weichsel, Vistula], walled round, Full off Turretts, 9 or 10 gates, Faire large straightt streetes, the best Councell house in all this Country, somewhatt resembling an exchange, very large and high, 4 square, a space in the Middle, a lofty costly tower to itt" [tłum. B.A.]. 
ści i położenia z Londynem, ma układ nieco swobodniejszy: po ocenie położenia i wielkości miasta Mundy przechodzi do charakterystyki ulic i domów („Streets and houses”), lecz przed opisem murów miejskich („The Citty wall”) i Wielkiej Zbrojowni („Zeugh-hause or munition house”) ${ }^{28}$ wspomina, jakie religie wyznają mieszkańcy Gdańska i podaje opis kościoła Mariackiego („Pffarre kerke”), będący jednak formalną ekfrazą jedynie częściowo, gdyż angielskiego podróżnika zainteresowały przede wszystkim dwa elementy wyposażenia świątyni, oto po przedstawieniu rozmiarów kościoła (nieznacznie tylko mniejszy od katedry św. Pawła w Londynie) skupia się niemal wyłącznie na dzwonach i zegarach gdańskiej świątyni. Do kościoła Mariackiego powraca Mundy jeszcze w dalszej narracji, by opisać znajdujące się tam wielkie organy („The great Organs in the Pfarrekerke”) ${ }^{29}$. Analogicznym, bardzo typowym dla angielskiego podróżnika odstępstwem od klasycznej teorii opisu czy też pochwały miast jest też obszerny opis toruńskiego mostu jako jedyny toruński akcent w relacji XXXV ${ }^{30}$. Owo skupienie się na wybranych obiektach jest niewątpliwie rysem bardzo osobistym - Mundy dokładnie opisuje to, co go faktycznie zainteresowało, nie bacząc na kompozycję całości.

Za rys osobisty Anglika można również uznać większe, niż zalecał Bucoldianus, skupienie się na mieszkańcach opisywanych ziem i miast. Mundy obszernie opisuje zatem rozrywki w Gdańsku („Recreations in Dantzigh”), odnotowuje fakt wystawiania w mieście angielskich dramatów („English plaiers or commediens") czy też opisuje różne typy ludzkie: polskie i gdańskie, które można spotkać w mieście ${ }^{31}$. Dodaje do nich również swoje rysunki ${ }^{32}$. Owo zainteresowanie raczej życiem ludzi w pruskich miastach niż ich architekturą widać również w dokładnym opisie „wielkiego jarmarku” („A greatt faire”) ${ }^{33}$, czyli jarmarku Trzech Króli w Toruniu, dłuższym niż opis całego miasta, a ustępujący jedynie opisowi mostu w „relacji” XXXV.

Przedstawione tu uwagi na temat opisów Gdańska i Torunia, które wyszły spod pióra Petera Mundy'ego, skonfrontowane z jednym z najobszerniejszych i jednocześnie bardzo powszechnie dostępnym wykładem teorii ekfrazy miast, prowadzą do konkluzji, że angielski podróżnik owej teorii najprawdopodobniej był świadom. Szczególnie początek charakterystyki Torunia jest wierny

\footnotetext{
${ }^{28}$ Zob. ibid., s. $170-172$.

${ }^{29}$ Zob. ibid., s. 186.

${ }^{30}$ Zob. ibid., s. 196-197.

${ }^{31}$ Zob. ibid., s. 177-179, 181-182, 190-192.

${ }^{32}$ Zob. ibid., plansza X, il. 11.

${ }^{33}$ Zob. ibid., s. 100-101.
} 
zalecanej przez Bucoldianusa kolejności: położenie - obwarowania - budowle wewnątrz murów. Mundy jednak jako autor nieograniczony konwencją piśmiennictwa okolicznościowego odcisnął na swych opisach silnie indywidualne piętno; skupił się na interesujących go budowlach, przedmiotach, zwłaszcza na tych, w których, jak w przypadku gdańskich organów lub w toruńskim moście, zaobserwował ciekawe rozwiązania techniczne, oraz na obyczajach ludności, które opisuje zwykle bez wartościujących komentarzy.

Nadesłany 1 X 2018

Nadesłany po poprawkach 29 XI 2018

Zaakceptowany 14 XII 2018

Dr hab. Bartosz Awianowicz, prof. UMK

Katedra Filologii Klasycznej

Uniwersytet Mikołaja Kopernika w Toruniu

e-mail: bartosz.awianowicz@umk.pl

ORCID ID: 0000-0001-7380-2272

Descriptions of Gdańsk and Toruń in the Accounts by Peter Mundy:

BETWEEN AN ENGLISHMAN'S SinCERE CURIOSITY

AND EARLY MODERN THEORY OF EKPHRASIS

Abstract

Key words: Peter Mundy, Gerard Bucoldianus, Gdańsk, Toruń, rhetoric, ekphrasis, travel literature, curiosity

Peter Mundy (1596 - ca. 1667), one of the most representative English travellers of his period, visited Gdańsk (Danzig) and Torun (Thorn) in 1640 and 1642 and described these cities in his Relations. The article includes deliberations concerning Mundy's descriptions of the two most important cities in Royal Prussia in the context of early modern theory of ekphrasis and the eulogy of the city, represented especially by manuals of preliminary exercises in rhetoric (progymnasmata) and chapters from De inventione et amplificatione oratoria by Gerard Bucoldianus included in Reinhard Lorich's Scholia attached to his edition of Aphthonius' Progymnasmata, one of the most popular rhetoric books in the second half of $16^{\text {th }}$ and in $17^{\text {th }}$ centuries. The analysis of the structure and contents of Mundy's "relations" leads to the conclusion that the English traveller was aware of the early modern theory of description and eulogy of cities but, at the same time, his curiosity made him free to leave the theoretical rules aside and focus himself on interesting technical constructions ("The great Organs in the Pfarrekerke" in Gdańsk or the Torun bridge) or customs of burghers ("execution of Justice" and "Recreations" in Gdańsk and "A greatt faire" in Toruń). 


\author{
Beschreibungen von Danzig und Thorn \\ in den Berichten von Peter Mundy. \\ ZWisCHEN DER EHRLICHEN NEUGIER EINES ENGLÄNDERS \\ UND DER FRÜHNEUZEITLICHEN EKPHRASIS-THEORIE
}

\begin{abstract}
Schlüsselwörter: Peter Mundy, Gerard Bucoldianus, Danzig, Thorn, Rhetorik, Ekphrasis, Reiseliteratur, Neugier

Peter Mundy (1596 - ca. 1667) war einer der repräsentativsten englischen Reisenden seiner Zeit. 1640 und 1642 besuchte er Danzig und Thorn und beschrieb beide Städte in seinen Relations. Der vorliegende Artikel enthält Überlegungen zu Mundys Beschreibungen der beiden wichtigsten Städte im Königlichen Preußen im Zusammenhang der frühneuzeitlichen Theorie der Ekphrasis und des Städtelobs, wie sie sich vor allem in Lehrbüchern mit Vorübungen zur Rhetorik (progymnasmata) und in Kapiteln aus De inventione et amplificatione oratoria von Gerald Bucoldianus finden. Diese sind enthalten in den Scholia von Reinhard Lorich, die seiner Ausgabe der Progymnasmata des Aphtonios angefügt sind, einem der populärsten Bücher über Rhetorik in der zweiten Hälfte des 16. und im 17. Jahrhundert. Eine Analyse der Struktur und des Inhalts der Relations von Mundy führt zu dem Schluss, dass der englische Reisende von der Existenz der frühneuzeitlichen Theorie der Beschreibung und des Lobs von Städten wusste, dass seine Neugierde es ihm aber erlaubte, die theoretischen Regeln über Bord zu werfen und sich auf interessante technische Konstruktionen („The great Organs in the Pfarrekerke" in Danzig und die Brücke in Thorn) oder auf die Gewohnheiten der Bürger („execucion of Justice“ und „Recreations“ in Danzig, aber auch „A greatt faire“ in Thorn) zu konzentrieren.
\end{abstract}

\title{
Bibliografia
}

Awianowicz, Bartosz B. "Die Progymnasmata-Sammlungen und der Glaubenskampf des 17. Jahrhunderts." In Welche Antike? Konkurrierende Rezeptionen des Altertums im Barock, vol. 1, edited by Ulrich Heinen, 477-489. Wiesbaden: Harrassowitz Verlag, 2011.

Awianowicz, Bartosz B. Progymnasmata $w$ teorii i praktyce szkoły humanistycznej od końca XV wieku do połowy XVIII wieku. Dzieje nowożytnej recepcji Aftoniosa od Rudolfa Agricoli do Johanna Christopha Gottscheda. Toruń: Wydawnictwo Naukowe UMK, 2008.

Awianowicz, Bartosz B. “'Urbes laudandi ratio’. Antyczna teoria pochwały miast i jej recepcja w 'De inventione et amplificatione oratoria' Gerarda Bucoldianusa oraz w 'Essercitii di Aftonio Sofista' Orazia Toscanelli.” Terminus 11/1-2 (2009): 15-32.

Baldwin, Thomas Whitfield. William Shakespere's Small Latine \& Lesse Greek, vol. 2. Urbana: University of Illinois Press, 1944. 
Carrington, Dorothy. The Traveller's Eye. London: Readers Union, 1949.

Classen, Carl Joachim. Die Stadt im Spiegel der Descriptiones und Laudes urbium in der antiken und mittelalterlichen Literatur bis zum Ende des zwölften Jahrhunderts. Hildesheim: Olms, 1980.

Evans, Robert J. W. and Alexander Marr, eds. Curiosity and Wonder from the Renaissance to the Enlightenment. Aldershot: Ashgate Publishing, 2006.

Green, Lawrence D. and James J. Murphy. Renaissance Rhetoric. Short-Title Catalogue 1460-1700. Hunts: Ashgate Publishing, 2006.

Krzywy, Roman. "Deskrypcja Stambułu w 'Przeważnej legacyi’ Samuela Twardowskiego wobec topiki laudatio urbis." Pamiętnik Literacki 102/4 (2011): 41-58.

Krzywy, Roman. Wędrówki z Mnemozyne. Studia o topice dawnego podróżopisarstwa. Warszawa: Muzeum Pałacu w Wilanowie, 2013.

Lausberg, Heinrich. Retoryka literacka. Podstawy wiedzy o literaturze. Translated and edited by Albert Gorzkowski. Bydgoszcz: Homini, 2002.

Pomponiusz Mela. Chorograpphia czyli Opis kregu Ziemi. Edited by Sergiusz Szarypkin and Krzysztof Tomasz Witczak, translated by Marian Golias and Krzysztof Tomasz Witczak. Piotrków Trybunalski: Naukowe Wydawnictwo Piotrkowskie, 2011.

Rybiński, Jan. Księga elegii podróżnych. Translated by Elwira Buszewicz, introduced and edited by Elwira Buszewicz and Wojciech Ryczek. Warszawa: Wydawnictwo Naukowe Sub Lupa, 2015.

Temple, Richard Carnac, ed. The Travels of Peter Mundy in Europe and Asia 1608-1667, vol. 1-5. London: Hakluyt Society, 1907-1936.

White, Agnieszka. Obraz kultury Rzeczypospolitej w angielskich relacjach podróżniczych (koniec XVI $i$ XVII wiek). Warszawa: nakł. Wydziału Polonistyki Uniwersytetu Warszawskiego, 2014.

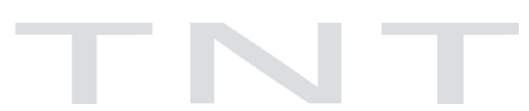

